\title{
HIGH SPEED ANISOTROPIC ETCHING OF GLASS AND PIEZOCERAMICS FOR MICROSYSTEM APPLICATIONS
}

\author{
Abhijat Goyal, Srimath S. Subasinghe, Vincent Hood, and Srinivas Tadigadapa \\ Department of Electrical Engineering, Penn State University, University Park, PA - 16802
}

\begin{abstract}
In this article, we present an inductively coupled plasma (ICP) based dry anisotropic dielectric etching process. The reactive ion etching system employed $\mathrm{SF}_{6} / \mathrm{Ar}$ based chemistry and was used to define high aspect ratio features in materials such as glass (Pyrex $\left.{ }^{\circledR} 7740\right)$, single crystal AT and Y cut quartz, and piezoceramics. An etch rate of $0.536 \mu \mathrm{m} / \mathrm{min}$ at a rms surface roughness of $1.97 \mathrm{~nm}$ was obtained for Pyrex samples using an optimized recipe comprising of $\mathrm{SF}_{6}$ flow rate of $5 \mathrm{sccm}$, Ar flow rate of $50 \mathrm{sccm}, 2000 \mathrm{~W}$ of ICP power, $475 \mathrm{~W}$ of substrate power, substrate holder temperature of $20^{\circ} \mathrm{C}$, and distance of substrate holder from ICP source to be $120 \mathrm{~mm}$. Use of a similar recipe to etch bulk lead zirconate titanate (PZT) resulted in an etch rate of $0.32 \mu \mathrm{m} / \mathrm{min}$. We used Design of Experiment (DOE) methodology to optimize the etching process with respect to etch rate and rms surface roughness. Regression using least square fit was used to define an arbitrary etch rate number $\left(W_{\text {etch }}\right)$ and an rms surface roughness number $\left(W_{r m s}\right)$ as a function of eight correlated process parameters, namely ICP power $\left(W_{I C P}\right)$, substrate power $\left(W_{\text {sub }}\right)$, flow rate of gases $\left(Q_{S F 6}, Q_{A r}\right)$, operating pressure $\left(P_{\text {process }}\right)$, temperature of substrate $\left(T_{\text {sub }}\right)$, and the distance of the substrate from the source $(D)$. The etching process, its optimization and quantification techniques presented in this article present very useful tool for MEMS fabrication and packaging applications.
\end{abstract}

\section{INTRODUCTION}

Future innovations and improvements in navigational grade inertial microsensors, optical waveguides, high frequency crystal oscillators and filters, microactuators, and nano air vehicles etc. are going to increasingly rely on the successful micromachining of materials such as glass, quartz, piezoelectric ceramics etc. A high speed, anisotropic, etch process is required for defining high aspect ratio features to realize resonators, actuators, and passive structural elements in a microsystems. In this study, we used an inductively coupled plasma based reactive ion etching system employing $\mathrm{SF}_{6} / \mathrm{Ar}$ chemistry to accomplish high speed anisotropic etching of quartz, Pyrex, bulk PZT, etc. We present results on process optimization to achieve high etch rate along with minimum rms surface roughness of the etched features. Control over the properties of etched surfaces is important for MEMS devices given their large surface area to volume ratio. Surface imperfections results in creation of loss channels in active components, and structural defects in passive components, resulting in loss of microsystem functionality and reliability.

Pyrex substrates were used for optimizing the etch process for quartz, glass, etc. For the etch process optimization for piezoceramics, PZT-4 substrates were used. The 4" Pyrex ${ }^{\circledR} 7740$ wafers (double sided polished) were cleaned thoroughly with Acetone/Isopropyl Alcohol (IPA) followed by piranha clean (1:1 $\mathrm{H}_{2} \mathrm{SO}_{4}: \mathrm{H}_{2} \mathrm{O}_{2}$ ) for one hour. A seed layer, consisting of $200 \mathrm{~nm}$ of gold with $20 \mathrm{~nm}$ of chromium as an adhesion layer, was subsequently e-beam evaporated on the cleaned glass (Pyrex ${ }^{\mathbb{B}}$ 7740) surface. The etch patterns were then delineated on the seed layer using standard lithography and wet etching steps [1]. The patterned 4" wafers were diced into individual 1" dies. A thick layer $(5-10 \mu \mathrm{m})$ of nickel was then electroplated onto the seed layer on the 1" dies. A standard run time of one hour was used for all the samples.

In the case of PZT substrates, finely lapped PZT-4 substrates were cleaned using acetone/isopropyl alcohol (IPA) followed by descumming in oxygen plasma. A $100 \mathrm{~nm}$ chromium (Cr) adhesion layer and $350 \mathrm{~nm}$ gold (Au) seed layers were deposited via electron beam evaporation on the cleaned PZT substrates. A thick Ni layer $(2-5 \mu \mathrm{m})$ was then electroplated on the Au seed layer. The electroplated PZT substrates were thereafter diced into smaller 1 $\mathrm{cm}$ square dies. The PZT dies were mounted onto an aluminum substrate using Fomblin ${ }^{\mathrm{TM}}$ oil. After the etching step, the Ni hard mask was stripped using isotropic wet etching of the gold seed layer. The details of the fabrication sequence can be found

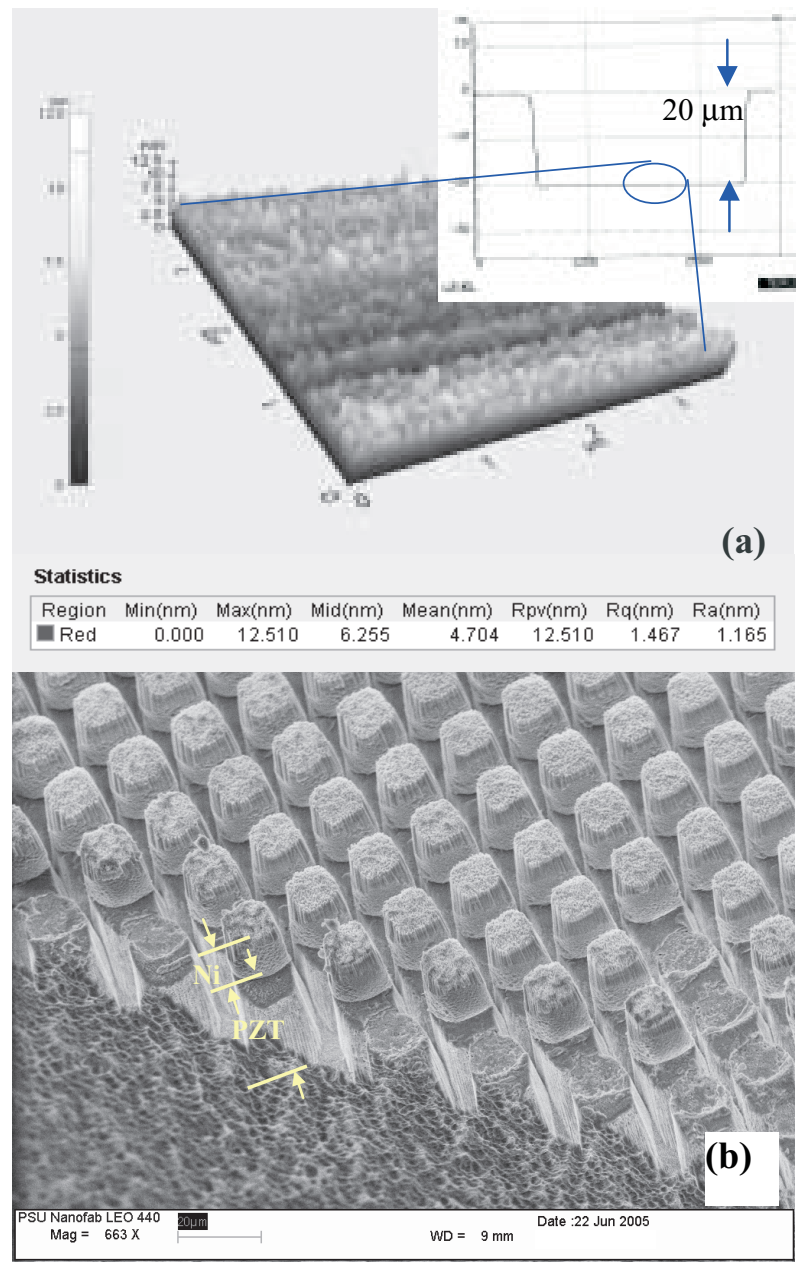

Figure 1: (a)Alpha-step and AFM image of the surface obtained after 1 hour $(20.3 \mu \mathrm{m})$ etching of Pyrex (b) SEM image of the etched feature in bulk PZT for minimum feature size of $3 \mu \mathrm{m}$. Almost vertical sidewalls were obtained. Also can be seen is the electroplated nickel on the top of the pillars acting as a hard mask during the etching process. 
elsewhere [2-4].

For both the samples, the etch rate was determined from the step height of the etched feature. The rms surface roughness (only for the etched Pyrex substrates) along with step height (for both the substrates) was measured using a stylus profilometer. Additionally, atomic force microscope (AFM) and scanning electron microscope (SEM) was used to characterize the properties of the sidewalls and for accessing the quality of the etched features in terms of their rms surface roughness.

\section{DESIGN OF EXPERIMENT (DOE)}

One of the primary problems with the optimization of etching process is the large number of process variables and the complex interaction between them. It typically requires an impractically large number of runs to come up with the optimized process to obtain the desired etch rates and the rms surface roughness. Use of scientific process optimization methods such as Design of Experiment (DOE) can traditionally reduce the number of runs required. However, even then the number of runs can be too large to be practical. For example, in one of the related studies, we used a combination of $\mathrm{SF}_{6} / \mathrm{C}_{4} \mathrm{~F}_{8} / \mathrm{Ar} / \mathrm{O}_{2} / \mathrm{CH}_{4}$ based chemistry for etching Pyrex [3]. Optimization of the etching process with such a large number of variables, 10 in that case will typically require $2^{10}$ (1024) sample runs. In such as a case, the process space can be divided into subspaces to further reduce the number of runs.

\section{A. Etching of Pyrex}

For the Pyrex wafers, a standard DOE methodology employing two factorial design was used to study the variation of etch rate and rms surface roughness as a function of the process parameters. We optimized the process conditions to obtain the highest etch rate with minimum possible surface roughness. Four process parameters, ICP power $(500 \mathrm{~W}-2000 \mathrm{~W})$, substrate power $(100 \mathrm{~W}-475 \mathrm{~W}), \mathrm{SF}_{6}$ flow rate $(5 \mathrm{sccm}-50 \mathrm{sccm})$ and Ar flow rate $(5 \mathrm{sccm}-50 \mathrm{sccm})$ were optimized as part of DOE. It was possible to obtain an etch rate of $0.536 \mu \mathrm{m} / \mathrm{min}$ and $\mathrm{rms}$ surface roughness of $1.97 \mathrm{~nm}$ at an ICP power of $2000 \mathrm{~W}$, substrate power of $475 \mathrm{~W}, \mathrm{SF}_{6}$ flow rate of $5 \mathrm{sccm}$, and Ar flow rate of $50 \mathrm{sccm}$ [5]. The other process parameters were distance of the substrate holder from the source which was fixed to be $120 \mathrm{~mm}$, temperature of substrate holder which was fixed at $20^{\circ} \mathrm{C}$. The pumping system was operated at full capacity so that the pressure during etching was between 1-2 mTorr. Figure 1 (a) shows the AFM image of the surface generated after the etch step. Also shown in inset of Figure 1 (a) is the side view of the etch profile. Almost vertical side walls were obtained. The apparent non-vertical angle of the sidewall in the stylus profile is due to finite dimension of the tip of the profilometer and hence is not a true measure of the sidewall angle.

The etch rate and rms surface roughness were found to improve with increasing ICP power, substrate power, and Ar flow rate (Figure 2 (a), (b), and (c)). However, for increasing flow rate of $\mathrm{SF}_{6}$, the etch rate increased whereas rms surface roughness decreased (Figure 2(d)). For increasing operating pressure (Figure 2(e)) and distance of substrate from source (Figure 2(f)), both the etch rate and rms surface roughness deteriorated.

\section{B. Etching of bulk PZT}

In this case, we optimized the process conditions to get the best etch rate, and we did not consider the rms surface roughness of the etched features. The focus was on achieving maximum

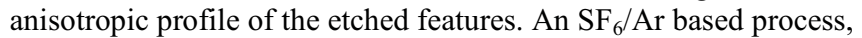
similar to the one used for etching Pyrex, was used to etch PZT. A high etch rate of $0.32 \mu \mathrm{m} / \mathrm{min}$ was achieved. Figure 1(b) shows 3 micron by 3 micron pillars etched into bulk PZT ceramic substrates using optimized $\mathrm{SF}_{6} / \mathrm{Ar}$ based chemistry. As in the case of Pyrex etching, the etch rate increased with increasing ICP power, substrate power, and increasing flow rates of Argon and $\mathrm{SF}_{6}$ (Figure 3 (a), (b) and (c)).

Given the same recipe that was used to etch Pyrex worked for etching of PZT, the authors believe that the optimized process is similar to ion milling $[6,7]$, with addition of $\mathrm{SF}_{6}$ providing the chemistry and enhancing the etching process. Without the chemistry provided by fluorine ions and radicals, the etching process in ion milling primarily relies on eroding the surface using incident energetic ion beam. In the present case, the fluorine ions and radicals react with atoms on the surface of the sample (Pyrex or PZT), forms reaction products and the incident beam of energetic ions aids in the desorption of the reaction products from the surface of the sample. Also, the incident ions help in deeper penetration of fluorine based ions and radicals into the surface of
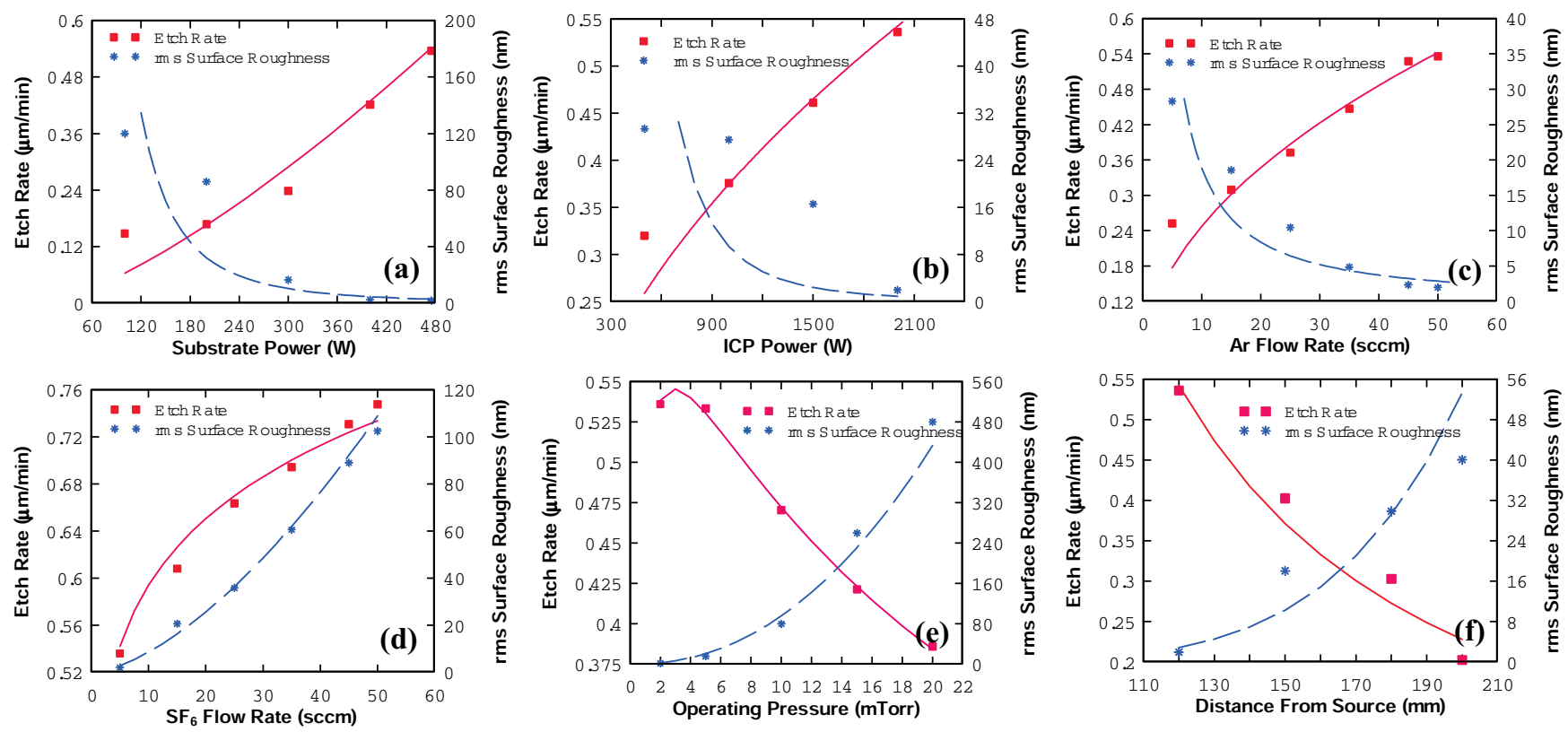

Figure 2: Variation of etch rate and rms surface roughness with (a) Substrate Power, (b) ICP power, (c) Ar flow rate, (d) SF 6 flow rate, (e) operating Pressure and (f) Distance from source for etching of Pyrex. The lines in the graphs are fit to the data and are given by equations 1-6 in the text. 

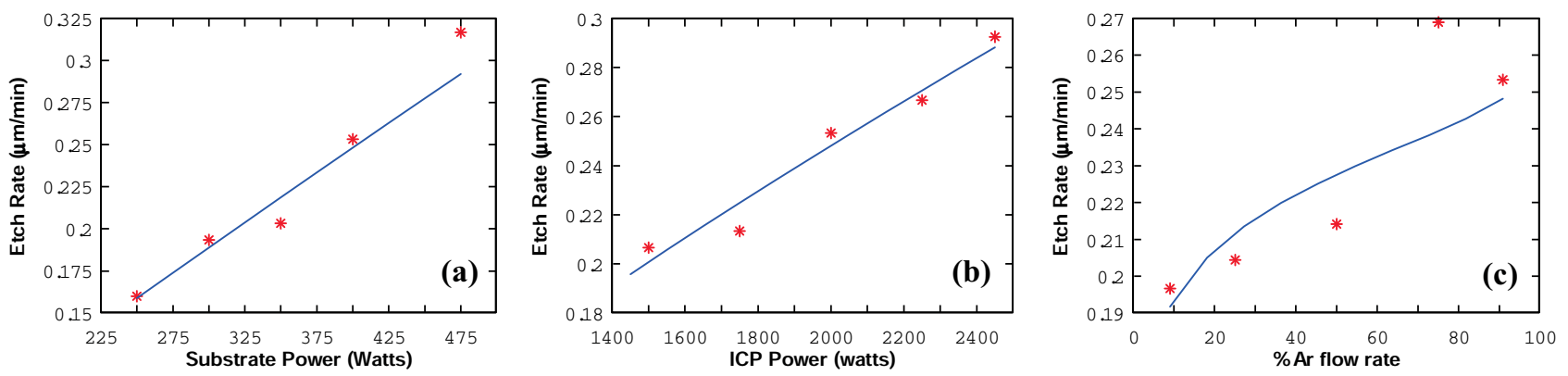

Figure 3: Variation of etch rate as a function of (a) Substrate Power, (b) ICP Power, and (c) Ar and SF flow rate for bulk PZT substrate. The solid lines are fits to the data according to equations 7 and 8 , as given in the text.

the sample, thereby accelerating the etching process.

\section{REGRESSION FOR PROCESS QUANTIZATION}

For the quantification of the etch process, it is useful to define a quantitative measure of the etch rate and rms surface roughness in terms of process parameters. Etch characteristics which vary monotonically with respect to the process parameters can be easily modeled using power law. Use of such power law metrics, for parameters which do not vary monotonically with process parameters, results in significant errors in the quantization process. However such errors can be significantly reduced by use of additional higher order terms in the quantization metric. For the quantization process, the data was arranged in a $m$ by $(n+1)$ matrix, where $m$ are the total number of runs and $n$ is the total number of process parameters used in the quantization process. The last column in the matrix consists of value of the etch parameter, i.e. rms surface roughness or etch rate, that is being quantized. This is followed by using a computer program such as Mathematica ${ }^{\circledR}$ to regressively fit a nonlinear power law equation by minimizing the least square error. The fitting equation can be expressed as -

$$
\ln (W)=\ln \left(a_{0}\right)+\sum_{i=1}^{n} a_{i} \ln \left(P P_{i}\right)+\sum_{k=2}^{3} \sum_{j=1}^{n} a_{j} \ln \left(P P_{j}^{k}\right)
$$

where, $W$ is the arbitrary number relating etch characteristics to the process parameters, $a_{i}$ and $a_{j}$ are the fitting parameters, $P P_{j}$ are the process parameters whose effect on the etch characteristics are being quantized. Rewriting the equation by taking exponentials on both sides -

$$
W=a_{0}\left(\prod_{i=1}^{n} P P_{i}^{a_{i}}\right) \exp \left[\sum_{k=2}^{3} \sum_{j=1}^{n} a_{j} \ln \left(P P_{j}^{k}\right)\right]
$$

which is the form of equation that is being used in this paper to express the etch parameters in terms of process parameters. The higher order terms, given by the third term in equation (1) are required only when the variation of etch characteristics with respect to process parameters is not monotonic. We can call these terms as "correction factors" to the power law model used for the quantization process. The correction terms are a result of interaction between different components of the process space or where the change in etch parameters as a function of process parameters is not monotonic. Without the correction factors the spread of data is significant and hence the description in terms of the reduced etch parameters becomes less meaningful.

(a) For $\mathrm{SF}_{6} / \mathrm{Ar}$ based Pyrex etching: From the least square fit to the data in our experiments, an etch rate number $\left(W_{\text {etch }}\right)$ was defined, as

$$
W_{\text {etch }}=\frac{W_{I C P}^{0.52} W_{\text {sub }}^{1.36} Q_{S F_{6}}^{0.135} Q_{A r}^{0.48} T_{\text {sub }}^{0.065} P_{\text {process }}^{0.2}}{\mathrm{D}^{1.67}} \exp \left(-0.094\left(\ln P_{\text {process }}\right)^{2}\right)
$$

where $W_{I C P}$ is the ICP power in Watts, $W_{\text {sub }}$ is the substrate power in Watts, $Q_{S F 6}$ is the flow rate of $\mathrm{SF}_{6}$ in sccm, $Q_{A r}$ is the flow rate of $\mathrm{Ar}$ in sccm, $T_{\text {sub }}$ is the substrate temperature during the process in ${ }^{\circ} \mathrm{C}, P_{\text {process }}$ is the ambient pressure during the process in mTorr, and $D$ is the distance from the ICP source of the substrate holder in $\mathrm{mm}$. The etch rate can now be defined as -

$$
R_{\text {etch }}=a W_{\text {etch }} \text { or } \ln \left(R_{\text {etch }}\right)=\ln (a)+\ln \left(W_{\text {etch }}\right)
$$

where $R_{\text {etch }}$ is the etch rate in $\mu \mathrm{m} / \mathrm{min}$ and " $a$ " is a proportionality constant that relates etch rate to the etch rate number. The parameter $a$ and the powers of the process parameters in equation (3) were determined using least square fit to the data. The value of $\ln (a)$ from the least square fit from the data was obtained to be 3.2. Expression of the data in this form results in the plot of $\ln \left(R_{\text {etch }}\right)$ with respect to $\ln \left(W_{\text {etch }}\right)$ to be a straight line with a slope of unity as shown in Figure 4 (a). A surface roughness number $\left(W_{\text {rough }}\right)$ was defined in a similar way as

$$
W_{\text {rough }}=\frac{Q_{S F_{6}}^{1.58} P_{p \text { rocess }}^{2.18} \mathrm{D}^{5.726} T_{\text {sub }}^{0.197}}{W_{I C P}^{3.173} W_{\text {sub }}^{2.8} Q_{A r}^{1.172}}
$$

where the parameters are defined as in equation (3). The rms
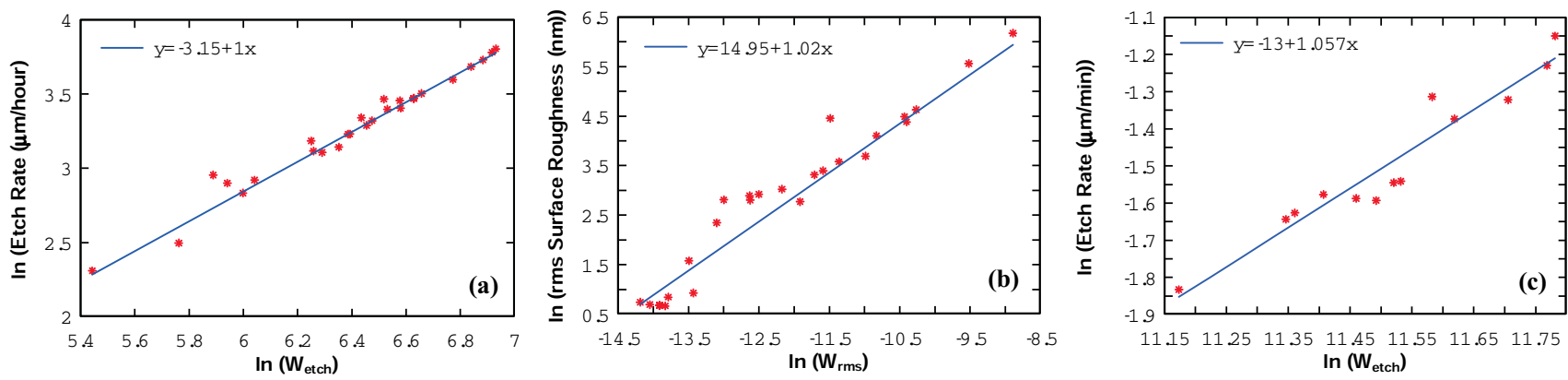

Figure 4: Plot of natural logarithms of etch rate number and the etch rate, and natural logarithms of rms surface roughness number and the rms surface roughness for $S F_{d} /$ Ar chemistry (a) and (b) Pyrex, and (c) for PZT. 
surface roughness can now be defined as -

$$
R_{\text {rough }}=b W_{\text {rough }} \text { or } \ln \left(R_{\text {rough }}\right)=\ln (b)+\ln \left(W_{\text {rough }}\right)
$$

The parameter " $b$ " and the powers of the process parameters in equation (5) were determined using least square fit to the data. The value of $\ln (b)$ from the least square fit from the current data was obtained to be 14.95 . The plot of $\ln \left(R_{\text {rough }}\right)$ to $\ln \left(W_{\text {rough }}\right)$ lie along a straight line with a slope of unity as shown in Figure 4 (b). Once etch rate and rms surface roughness numbers are defined for a given etch tool and a given material, it can be used to predict the expected etch rate for any given set of process parameters.

(b) For $\mathrm{SF}_{6} / \mathrm{Ar}$ based PZT etching: An etch rate number $\left(W_{\text {etch }}\right)$ was similarly defined as a function of the above four correlated process parameters for bulk PZT samples. The etch rate number was defined as follows -

$$
W_{\text {etch }}=\frac{W_{i c p}^{0.74} W_{s u b}^{0.95} Q_{A r}^{0.09}}{Q_{S F_{6}}^{0.018}}
$$

where $W_{i c p}$ is the top ICP power in watts, $W_{s u b}$ is the substrate power in Watts, $Q_{A r}$ is the flow rate of $\mathrm{Ar}$ and $Q_{S F 6}$ is the flow rate of $\mathrm{SF}_{6}$ in $\mathrm{sccm}$. The etch rate can now be defined as -

$$
R_{\text {etch }}=c W_{\text {etch }}
$$

where $R_{\text {etch }}$ is the etch rate in $\mu \mathrm{m} / \mathrm{min}$. As in the case of Pyrex, the constant " $c$ " and the exponents of the process parameters in equation (1) were obtained the fit of the etch data. As expected, expression of the etch data in this form results in graph of natural logarithm of $R_{\text {etch }}$ against the natural logarithm of $W_{\text {etch }}$ to be a straight line as shown in Figure 4(c). An $R^{2}$ value of 0.96 is obtained from the fit which indicates a good fit to the data with low spread of data points along the straight line. The value of constant " $c$ " was obtained to be $2.3 \times 10^{-6}$.

\section{CONCLUSIONS}

We have demonstrated a high speed dielectric etch process while maintaining control over the rms surface roughness of the etched features which is important for MEMS applications. We used an ICP-RIE system lined with magnets for generating high density plasma at minimum operating pressures (1-2 mTorr). By optimizing process conditions, we were able to obtain an etch rate of $0.536 \mu \mathrm{m} / \mathrm{min}$ and an rms surface roughness of $\sim 1.97 \mathrm{~nm}$ for Pyrex samples. At the same time, an etch rate of $0.32 \mu \mathrm{m} / \mathrm{min}$ was obtained for bulk PZT substrates. Using a standard factorial design of experiment methodology, we were able to ascertain effect of various process parameters on etch rate and rms surface roughness. Additionally quantitative metrics called etch rate number and rms surface roughness number were defined by least square fitting the etch data to a function dependent entirely on the process parameters. The demonstrated process can be used for rapid and controlled anisotropic etching of dielectrics for MEMS fabrication and packaging applications.

\section{ACKNOWLEDMENTS}

This work is supported by an NSF-NIRT grant, MCE 0096097.

\section{REFERENCES}

1. Madou, M.J., Fundamentals of Microfabrication: The Science of Miniaturization. 2nd Edition ed. 2002, Boca Raton, Florida: CRC Press.

2. Goyal, A., V. Hood, and S. Tadigadapa, High speed anisotropic etching of Pyrex(R) for microsystems applications. Journal of Non-Crystalline Solids. In Press, Corrected Proof.

3. Subasinghe, S.S., A. Goyal, and S.A. Tadigadapa. High aspect ratio plasma etching of bulk lead zirconate titanate. in Micromachining and Microfabrication Process Technology XI. 2006: SPIE.

4. Goyal, A., V. Hood, and S. Tadigadapa. High-speed anisotropic etching of quartz using SF[sub 6]/C[sub 4]F[sub 8]/Ar/O[sub 2] based chemistry in inductively coupled plasma reactive ion etching system. in Reliability, Packaging, Testing, and Characterization of MEMS/MOEMS V. 2006: SPIE.

5. Montgomery, D.C., Design and analysis of experiments. 6 ed. 2004: John Wiley and Sons.

6. Petit, D., et al., Nanometer scale patterning using focused ion beam milling. Review of Scientific Instruments, 2005. 76(2): p. 26105-1.

7. Fu, Y., Z. Shen, and N.K.A. Bryan, A novel harmless trimming for micro-device with defects and particles in arbitrary geometry by fine milling of focused ion beam. Microelectronics Journal, 2004. 35(2): p. 111-15. 